\title{
Erratum to: It Is a Two-Way Street: Using Storytelling and Narration as a Formalized Method to Promote Partnership Between the Instructors and ID Team in Higher Education Context
}

Yi Jin, Nadia Jaramillo Cherrez, Autumn N. Cartagena, and Wei Wang

\section{Erratum to:}

Chapter 7 in: B. Hokanson et al. (eds.), Educational Technology and Narrative, https://doi.org/10.1007/978-3-319-69914-1_7

The second author's name of chapter 7 was inadvertently mentioned as "N.J. Cherrez". It should have been "Jaramillo Cherrez, N".

This has been updated in the book's table of contents, list of contributors and the corresponding chapter opening page. 